\title{
Structural Changes in Starch Molecules during the Malting of Barley
}

\author{
Yukinobu Kano, Naoyuki Kunitake, Takuro KaraKawa, \\ Hajime TANIGUCHI* and Michinori NaKAMURA*
}

Research Laboratories, Sapporo Breweries Ltd., Meguro-ku, Tokyo 153, Japan

* Department of Agricultural Chemistry, The University of Tokyo, Bunkyo-ku, Tokyo 113, Japan

Received December 18, 1980

\begin{abstract}
Barley was made into a normal and an over-modified malt, and the loss in starch was $14.6 \%$ and $67.7 \%$, respectively. Starch granules, isolated from the barley and malts, were observed by scanning electron and light microscopes. In normal malt, $14 \%$ of the large granules were eroded and the small granules remained almost intact. In the case of over-modified malt, $38 \%$ of the large granules were eroded, and a marked reduction was found in the population of the small granules. lodine affinities and blue values of the starches increased as malting proceeded. The malting of barley resulted in an apparent increase in the amylose component of the starch but hardly affected its molecular size distribution when examined by Bio-Gel A-50m column chromatography. The fine structures of the barley and malt amylopectins were compared by Shephadex G-50 and Bio-Gel P-2 column chromatographies after debranching with pullulanase. No change was observed during malting in spite of a significant reduction in the amylopectin component of the starch.
\end{abstract}

Starch in the endosperm of barley consists of large $(15 \sim 20 \mu \mathrm{m}$ diameter $)$ and small $(<5 \mu \mathrm{m}$ diameter) granules. During the malting of barley, amylases have a limited action on the large granules, causing pits and endocorrosion channels, but rather rapidly degrading the small granules, when observed by a scanning electron microscope. ${ }^{1)}$ These changes are mainly found in the proximal (embryo) half of the endosperm.

According to Greenwood and Thomson, ${ }^{2,3)}$ the malting of barley causes a decrase in the starch content of the kernel by $16 \%$, an increase in the amylose content of the starch from 22 to $26 \%$, a very limited decrease in the degree of polymerization of the amylose from 1,800 to 1,500 , and a limited but significant reduction in the average chain length of the amylopectin from 26 to 18 glucose units, but little change in the internal chain length of the amylopectin. From these results they concluded that barley amylopectin undergoes enzymic attack resulting in a reduction only in the exterior chain length during malting. In their experiments starches were fractionated into amylose and amylopectin, the degree of polymerization of amylose was determined viscometrically, and the average chain length of amylopectin by the periodate oxidation method.

This paper reports structural comparisons carried out on starches from barley and malt by the gel chromatographic method, and the results which were different from those of Greenwood and Thomson were obtained.

\section{MATERIALS AND METHODS}

Barley and malt samples. Barley kernels of cvr. New Golden were made into normal and over-modified malts. The maiting conditions were as follows: Normal malt, barley was steeped at $15^{\circ} \mathrm{C}$ for 3 days till its moisture content was $44.8 \%$ and germinated at $15^{\circ} \mathrm{C}$ for 7 days. Over-modified malt, barley was steeped at $15^{\circ} \mathrm{C}$ for 4 days till its moisture content was $48.1 \%$ and germinated at $20^{\circ} \mathrm{C}$ for 10 days with an occasional spraying of water. Green malts thus prepared were kilned. Malting losses of normal and over-modified malts were $14.2 \%$ and $39.9 \%$ (dry basis), respectively. 
Determination of starch in barley and malt. Starch contents of the above samples were measured by the method of Pucher et al. ${ }^{4)}$

Isolation and purification of starch. Starch was isolated from unmalted barley and its malts essentially by the method of Greenwood and Thomson ${ }^{2 \prime}$ as described by Kano, ${ }^{5)}$ namely, protein was removed by shaking with toluene, and fat by refluxing with $85 \%$ methanol.

Scanning electron microscopy. The surfaces of starch granules were shadowed with gold and examined in a Hitachi-Akashi Scanning Electron Microscope, MSM-4.

Light microscopy. Starch granules suspended in water were examined in a haemocytometer. Eroded large-sized granules have furrows on the surface and are distinguishable from intact ones.

Iodine affinities. Iodine affinities of the starches were determined by the amperometric iodine titration method ${ }^{6)}$ The amylose content was calculated on the assumption that the iodine affinity of pure amylose is $19.0 \%$.

Blue values and wavelengths of the maximum absorbance $\left(\lambda_{\text {max }}\right)$ of starch-iodine complexes. Blue values and $\lambda_{\max }$ of the starches were determined by the method of Bourne $e t$ al. ${ }^{7}$

Bio-Gel A-50m column chromatography. Starch granules $(10 \mathrm{mg}$ ) were dissolved in $1 \mathrm{ml}$ of dimethyl sulfoxide by heating at $70^{\circ} \mathrm{C}$ for $3 \mathrm{hr}^{8)}$ After standing overnight at $37^{\circ} \mathrm{C}$, this solution was diluted with $2.5 \mathrm{ml}$ of $0.05 \mathrm{M}$ phosphate buffer $(\mathrm{pH} 6.9)$ and centrifuged $(1,000 \times g$ for $10 \mathrm{~min}$ ) to remove insoluble materials. Onto a Bio-Gel A$50 \mathrm{~m}(50 \sim 100 \mathrm{mesh})$ column $(2.64 \mathrm{~cm} \times 95 \mathrm{~cm})$, the supernatant $(3 \mathrm{ml})$ was applied and eluted downwards with $0.05 \mathrm{M}$ phosphate buffer $\left.(\mathrm{pH} 6.9)^{9}\right)$ at the rate of $24 \mathrm{ml}$ per hour at $20^{\circ} \mathrm{C}$. The effluent was collected in $8-\mathrm{ml}$ portions, and the carbohyrate content of each fraction was determined by the phenol-sulfuric acid method. ${ }^{10}$ An aliquot $(5 \mathrm{ml})$ of each fraction was mixed with $0.1 \mathrm{ml}$ of $0.02 \mathrm{M}$ $\mathrm{I}_{2}-\mathrm{KI}$ solution and its $\lambda_{\max }$ was estimated. ${ }^{11}$ The yield of carbohydrate recovered from the column was over $95 \%$.

Sephadex G-50 column chromatography after pullulanase treatment. After dissolution in $1 \mathrm{ml}$ of dimethyl sulfoxide as mentioned above and dilution with water, $\operatorname{starch}(5 \mathrm{mg})$ was incubated with Aerobacter pullulanase $\left(1,900 \mathrm{U}^{12}\right)$, which was kindly supplied by Mr. E. Sôma of Research Laboratories of Sapporo Breweries Ltd., in $6 \mathrm{ml}$ of $0.17 \mathrm{M}$ acetate buffer $(\mathrm{pH} 6.0)$ at $37^{\circ} \mathrm{C}$ for $24 \mathrm{hr}$. After the incubation, the reaction mixture was boiled for $5 \mathrm{~min}$. After removal of the precipitate by centrifugation $(1,000 \times g$ for $10 \mathrm{~min})$, the supernatant $(4 \mathrm{ml})$ was submitted to a Sephadex G-50 (fine) column chromatography, the conditions of which were identical with those described in the Bio-Gel A-50m column chromatography. The degree of polymerization $(D P)$ of the linear unit chains in each fraction was estimated by the method of Hizukuri et al. ${ }^{13)}(D P<20)$ or Bailey and Whelan ${ }^{14}$ $(D P>20)$. In the latter method, relationships between chain length and $\hat{t}_{\max }$ of starch-iodine complexes were used.

Bio-Gel P-2 column chromatography after pullulanase treatment. Bio-Gel P-2 ( 400 mesh) swelled in water was packed into a glass column $(2 \times 100 \mathrm{~cm})$. Two columns were connected in series (length, $200 \mathrm{~cm}$ ). Into the columns, $0.8 \mathrm{ml}$ of solution containing $c a .2 \mathrm{mg}$ of starch, which was treated with pullulanase as described above, was injected and eluted downwards with de-ionized and degassed water at the rate of $30 \mathrm{ml}$ per hour at $65^{\circ} \mathrm{C}$. Carbohydrates eluted from the columns were continuously analyzed in a JEOL JLC-6AH Carbohydrate Analyzer.

\section{RESULTS}

Barley was made into normal and overmodified malts, the losses of starch being $14.6 \%$ and $67.7 \%$, respectively (Table I).

Figures $1 \sim 3$ show scanning electron micrographs of unmalted barley, normal and over-modified malt starch samples. Some large starch granules from normal malt are eroded (Fig. 2), while no erosion is detected on the unmalted barley starch sample (Fig. 1). In the case of over-modified malt, a higher ratio of eroded large granules and an extensive erosion together with a marked reduction in the population of small granules are noticed (Fig. 3).

These morphological changes of barley

Table 1. Starch Contents of Barley and Malts

\begin{tabular}{lccc}
\hline \multicolumn{1}{c}{ Sample } & $\begin{array}{c}\text { Starch content } \\
(\% \text { dry basis })\end{array}$ & $\begin{array}{c}\text { Starch content } \\
(\mathrm{g} / 1,000 \text { grains })\end{array}$ & $\begin{array}{c}\text { Starch loss } \\
(\%)\end{array}$ \\
\hline Barley & 60.7 & 25.4 & - \\
Normal malt & 58.8 & 21.7 & 14.6 \\
Over-modified malt & 32.5 & 8.2 & 67.7 \\
\hline
\end{tabular}




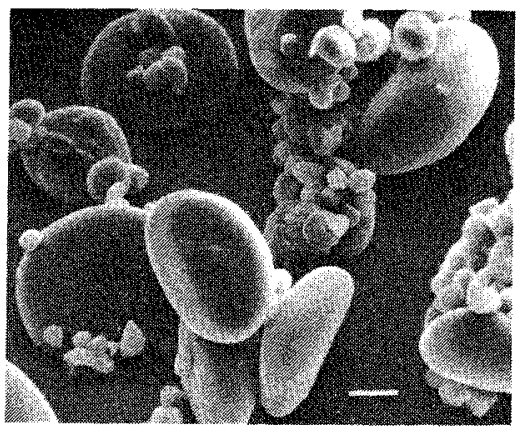

FIG. 1. Scanning Electron Micrograph of Barley Starch (Bar marker $=5 \mu \mathrm{m})$.

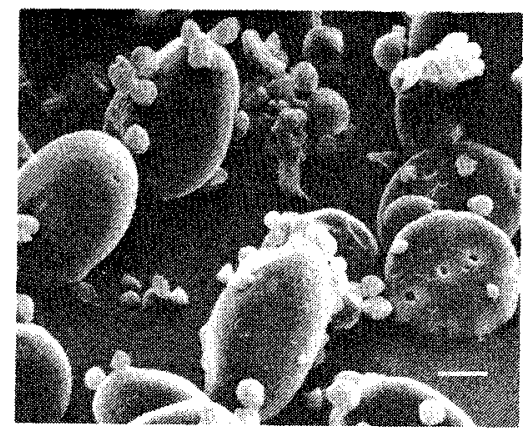

FIG. 2. Scanning Electron Micrograph of Normal Malt Starch $($ Bar marker $=5 \mu \mathrm{m})$.

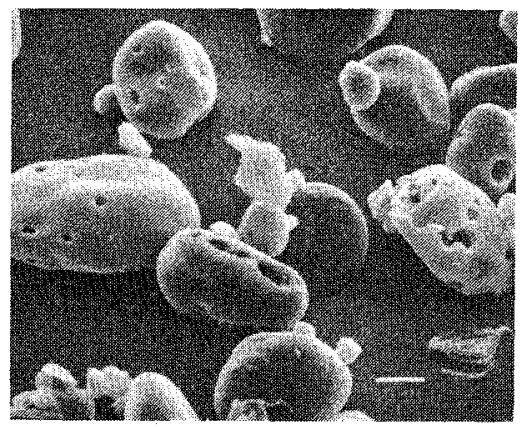

Fig. 3. Scanning Electron Micrograph of Over-modified Malt Starch (Bar marker $=5 \mu \mathrm{m})$.

starch during malting were quantitatively estimated by light microscopy and the results are summarized in Table II. The large starch granules of unmalted barley represent $13 \%$ of the total granules by number, this figure being quite close to that $(c a, 10 \%)$ reported by Bathate and Palmer. ${ }^{15)}$ The percentage by number of large granules in the normal malt
Table II. Proportions of Small/Large

Granules and Eroded/Intact Large Granules of Barley and MaLt Starches as Determined By a Light Microscope

\begin{tabular}{lcc}
\hline Sample & $\begin{array}{c}\% \text { Large } \\
\text { granules } \\
\text { (by number) }\end{array}$ & $\begin{array}{c}\% \text { Eroded } \\
\text { large granules } \\
\text { (by number) }\end{array}$ \\
\hline Barley & 13 & 0 \\
Normal malt & 15 & 14 \\
Over-modified malt & 39 & 38 \\
\hline
\end{tabular}

Table III. Properties of the Starches FROM BARLEY AND MALTS

\begin{tabular}{lcccc}
\hline \multicolumn{1}{c}{ Sample } & $\begin{array}{c}\text { Iodine } \\
\text { affinity } \\
(\%)\end{array}$ & $\begin{array}{c}\text { Blue } \\
\text { value }\end{array}$ & $\begin{array}{c}\lambda_{\max } \\
(\mathrm{nm})\end{array}$ & $\begin{array}{c}\text { Amylose } \\
\text { content } \\
(\%)\end{array}$ \\
\hline Barley & 4.6 & 0.41 & 615 & 24.2 \\
Normal malt & 4.8 & 0.43 & 617 & 25.3 \\
Over-modified malt & 5.1 & 0.45 & 620 & 26.9 \\
\hline
\end{tabular}

starch remained almost unchanged, bue increased remarkably $(39 \%)$ in the overmodified malt starch. The percentage of eroded large granules increased from zero in the barley starch to 14 in the normal malt starch and reached 38 in the over-modified malt starch.

Table III shows comparisons of the properties of the three starches. Iodine affinities, blue values and amylose contents increase and wavelengths of the maximum absorbance of starch-iodine complexes shift to longer wavelengths as malting proceeds.

\section{Molecular size distribution of starch com- ponents}

Starch solutions were fractionated by column chromatography on Bio-Gel A-50m, which has a fractionation range of $10^{5}$ to $5 \times 10^{7}$ in molecular weight for globular proteins (Fig. 4). By examining wavelengths of the maximum absorbance of starch-iodine complexes in each fraction, it was proved that amylopectin was excluded at the void volume position, whereas amylose was fractionated as a broad peak (Fraction Nos. $42 \sim 70$ ). The 


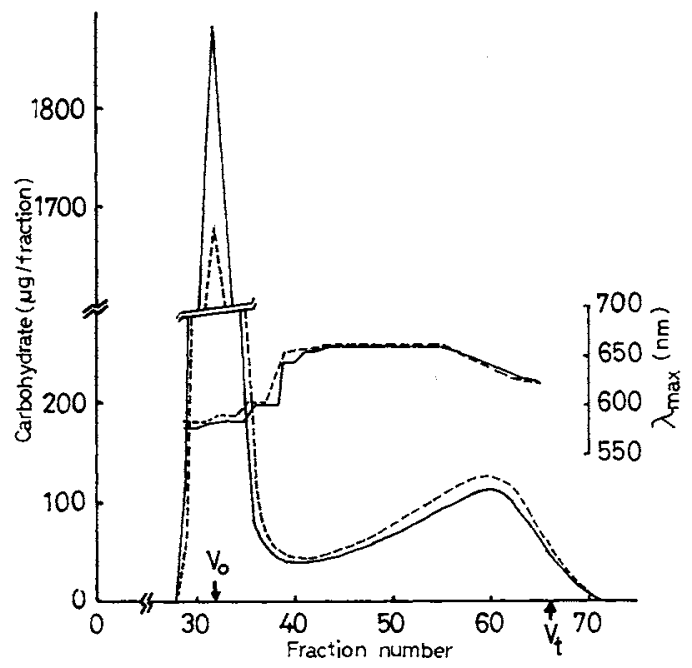

Fig. 4. Bio-Gel A-50m Column Chromatogram of Barley and Over-modified Malt Starches.

-., barley starch; ---, over-modified malt starch; $V_{o}$, void volume position; $V_{i}$, elution position of glucose.

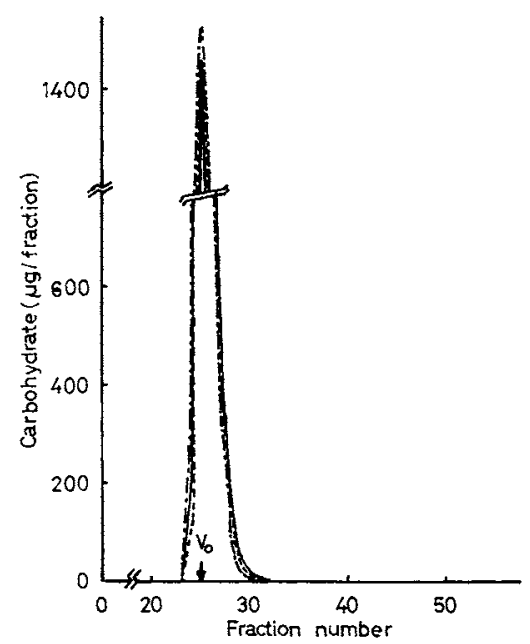

FIG. 5. Sephadex G-50 Column Chromatogram of Starches.

--, barley starch; - - - , normal malt starch; --.-., over-modified malt starch.

percentage of the amylose fraction of overmodified malt starch is 26 and higher by $3 \%$ compared with that $(23 \%)$ of barley starch, but little difference in the molecular size distribution of amylose fractions has been found between barley and over-modified malt starches. These percentages of the amylose

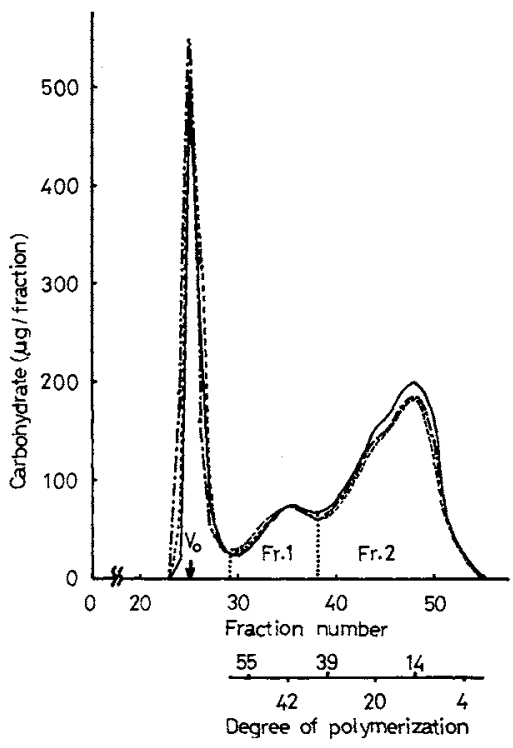

FIG. 6. Sephadex G-50 Column Chromatogram of Starches after Debranching with Pullulanase.

__, barley starch; _..., normal malt starch; ------, over-modified malt starch.

fractions are about the same with the amylose contents determined by the amperometric iodine titration method (Table III).

Chromatography on Bio-Gel A-15m, which has a fractionation range of $4 \times 10^{4}$ to $1.5 \times 10^{7}$ in molecular weight for globular proteins, excluded about a half of amylose and there was little difference between barley and malt starches in the molecular size distribution of lower molecular weight amyloses (data not shown).

Figure 5 shows Sephadex G-50 column chromatogram of starches. The degradation products of molecular weight lower than $10^{4}$ which is the exclusion limit of Sephadex G-50 neither exist in the normal nor in the overmodified malt starch granules.

\section{Fine structures of amylopectins}

Starch solutions, treated with pullulanase, were fractionated by Sephadex G-50 column chromatography (Fig. 6). Since the $\beta$-amylolysis limits after pullulanase treatment were over $99 \%$, debranching of the starches was considered almost complete. Debranched amylopectins (Fraction Nos. 29 55) were 
Table IV. The Fine Structures of

BaRLEY AND MALT AMYlopectins BASED ON FIG. 6

\begin{tabular}{lccc}
\hline Sample & $\begin{array}{c}\text { Fraction } \\
\text { Nos. 29 55 } \\
(\%)\end{array}$ & Fr. 2/Fr. 1 & $\begin{array}{c}\text { Average } \\
\text { chain } \\
\text { length }\end{array}$ \\
\hline Barley & 73 & 3.7 & 23 \\
Normal malt & 70 & 3.6 & 23 \\
Over-modified malt & 69 & 3.7 & 23 \\
\hline
\end{tabular}

a Anhydroglucose units.

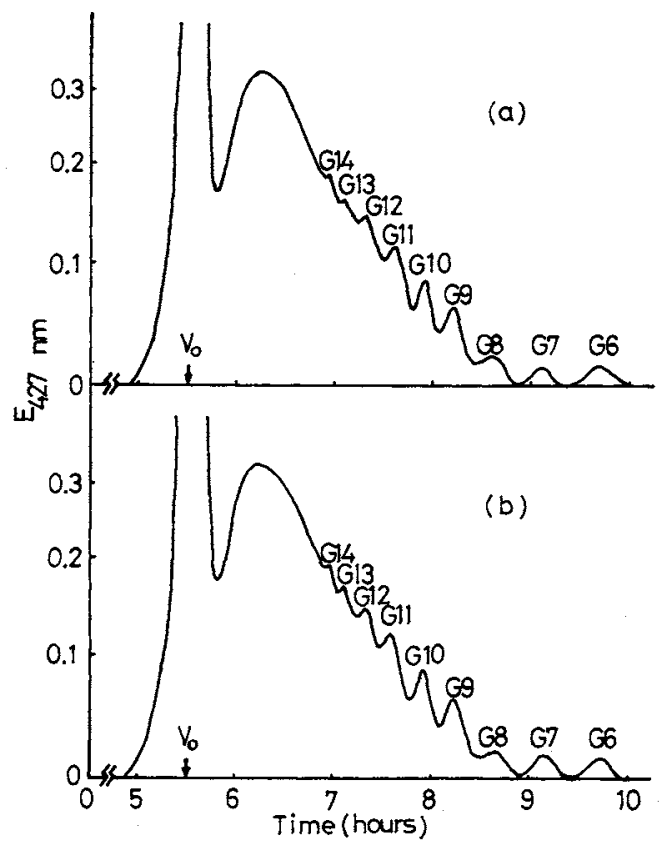

Fig. 7. Bio-Gel P-2 Column Chromatogram of Barley and Over-modified Malt Starches after Debranching with Pullulanese.

(a), barley starch; (b), over-modified malt starch.

fractionated into two fractions, Fr. 1 and Fr. 2, with $D P$ values at the apex of 42 and 14 , respectively, for all the starches. In addition each elution pattern had a shoulder near the apex of Fr. 2. From these elution patterns, the fine structures of amylopectins of the three starches are compared in Table IV. The percentage content of debranched amylopectin of normal malt starch decreases by $3 \%$ and that of over-modified malt starch by $4 \%$ compared with that of barley starch, but there are no differences between barley and malt starches in the Fr. 2 to Fr. 1 ratios and in the average chain lengths of amylopectins, which are calculated from the amount of carbohydrate and the drgree of polymerization in each fraction. Higher molecular weight materials excluded at the void volumn position (Fraction Nos. $24 \sim 29$ ) are amyloses, the percentages of which are 27, 30 and 31 for barley, normal and over-modified malt starches, respectively. These values are higher by several percent compared with the amylose contents determined by the amperometric iodine titration method (Table III).

After treatment with pullulanase, starches were further fractionated on a Bio-Gel P-2 column (Fig. 7). The eluate was analyzed automatically. By this column, oligosaccharides up to 14 glucose residues can be fractionated and quantitatively evaluated. There is neither any qualitative nor quantitative difference in the unit chains of $D P$ lower than 14 between barley and over-modified malt amylopectins.

\section{DISCUSSION}

Previously, Kano ${ }^{16)}$ investigated the differences in the structures of barley and maltedbarley starch components essentially by the method of Greenwood and Thomson. ${ }^{2,3)} \mathrm{A}$ part of the results is shown in Table $V$. Contrary to the results of Greenwood and Thomson, little change in the average molecular size of amylose and no change whatever in the average chain length of amylopectin were found.

In the previous study, ${ }^{16)}$ normal malts with starch losses of $12 \sim 18 \%$ were used. Greenwood and Thomson ${ }^{2}$ used malt with almost the same starch loss $(16 \%)$ as ours. In this study, in order to magnify the changes of properties of barley starch during malting, over-modified malt with starch loss of $67.7 \%$ was used in addition to normal malt with starch loss of $14.6 \%$ (Table I).

In the fractionation of starch components by selective precipitation with thymol and $n$ butanol, ${ }^{2)}$ there is a risk of losing components 
Table V. Comparisons of the Starches from Barleys and Malted Barleys

\begin{tabular}{|c|c|c|c|c|c|c|}
\hline \multirow[b]{2}{*}{ Source } & \multicolumn{3}{|c|}{ Amylose } & \multicolumn{3}{|c|}{ Amylopectin } \\
\hline & $\begin{array}{c}\text { Content } \\
(\%)\end{array}$ & $\begin{array}{l}\text { Iodine } \\
\text { affinity } \\
(\%)\end{array}$ & $\begin{array}{c}\text { Degree of } \\
\text { polymeirzation }^{a}\end{array}$ & $\begin{array}{l}\text { Iodine } \\
\text { affinity } \\
(\%)\end{array}$ & $\begin{array}{c}\beta \text {-Amylolysis } \\
\text { limit } \\
(\%)\end{array}$ & $\begin{array}{l}\text { Average chain } \\
\text { length }\end{array}$ \\
\hline \multicolumn{7}{|l|}{ Barley } \\
\hline A & 25.7 & 19.4 & 1,700 & 0.46 & 57 & 25 \\
\hline B & 25.1 & 19.9 & 1,800 & 0.33 & 57 & 25 \\
\hline $\mathrm{C}$ & 25.1 & 19.3 & 1,900 & 0.66 & 57 & 24 \\
\hline \multicolumn{7}{|c|}{ Malted barley } \\
\hline A & 27.6 & 19.4 & 1,700 & 0.66 & 57 & .24 \\
\hline B & 26.3 & 20.0 & 1,800 & 0.66 & 57 & 25 \\
\hline C & 26.2 & 19.9 & 1,800 & 0.67 & 55 & 25 \\
\hline
\end{tabular}

a Determined by the viscometric method. ${ }^{2)}$

${ }^{b}$ Determined by the periodate oxidation method. ${ }^{17)}$

of intermediate properties ${ }^{18)}$ between amylose and amylopectin. Moreover, only average values are obtained by the viscometric determination of the degree of polymerization of amylose and the determination of the chain length of amylopectin by the periodate oxidation method.

In this study, to avoid the above mentioned defects, analyses by the gel chromatographic method were tried.

During the malting of barley, a dicrease in the starch content of the kernel, morphological changes of starch granules (a reduction in the population of small granules and an appearance of pits and endo-corrosion channels in the partially-degraded large granules) and an increase in the amylose content of the starch were observed (Tables I \& II, Figs. $1 \sim 3)$. However, in accordance with the results in the previous study ${ }^{16)}$ (Table V), no changes in the structures of amylose as well as amylopectin were detected by the gel chromatographic techniques (Table IV, Figs. $4 \sim 7$ ).

The increase in the percentage of amylose during malting (Table III) is probably due to the preferential attack on amylopectin, and due neither to the synthesis of amylose nor to the conversion of amylopectin into amylose by debranching enzyme, because there are no differences in the molecular size distribution of amylose (Fig. 4) and in the fine structures of amylopectin (Table IV, Fig. 6) between barley and malt starches. Furthemore, the increase in the percentage of amylose during malting is not due to a reduction in the number of small granules (Table II), because there is no difference in the amylose content between large and small starch granules. ${ }^{19)}$ It seems that the degradation of starch proceeds in such a way that there are no degradation products with a molecular weight of at least lower than $10^{4}$ left in starch granules (Fig. 5).

In spite of the preferential attack on amylopectin during malting, we could not detect any change in the fine structures of the component. This result is considered to be due to any one of following three causes: (1) Changes in unit chain profile do occur during malting, but these changes are too small to be detected by the analytical methods used in this study. During malting, degradation of starch granules proceeds from the embryo end to the distal end and the distal end is left nearly as intact as in ungerminated barley, so all the starch granules are not degraded uniformly. Even in over-modified malt with a starch loss of $68 \%$, only $38 \%$ of the large granules have endocorrosion channels and the rest remains almost intact (Table II). (2) During malting, barley amylopectin suffers from such changes as can not be detected by the analytical methods used in this study. If we suppose, on the 
basis of the cluster hypothesis of amylopectin structure, ${ }^{20,21)}$ that amylopectin molecules are degraded in such a way that each cluster is taken away from the amylopectin molecule. as it is to give soluble products which are further degraded by the combined action of amylases, debranching enzymes and glycosidases, we can not detect any difference in the G-50 column chromatogram after the debranching of amylopectin. (3) During malting, enzymes attack starch granules in such a way that an amylopectin molecule, if it occurs, is hydrolyzed out completely; that is, no amylopectin molecule which was partially attacked remains in the malt starch granules.

Kiribuchi and Nakamura ${ }^{22,23)}$ germinated dehusked barley seeds (New Golden variety) in the presence of sufficient water at $20^{\circ} \mathrm{C}$ in the dark. Under these conditions, as the germination proceeded, smaller starch granules were preferentially degraded and there was an increase in the amylose component in the remaining starch, as evidenced by the increase in the blue value and wavelength of the maximum absorption of the iodine-starch color reaction. The average chain lengths of amylose and amylopectin showed a small decrease. These results and those obtained in this paper agree in some points and are contradictory in other points. The reason is not known at present, but the differences in the conditions between malting and germination and the methodology employed, may be responsible. The malting of barley for beer aims at obtaining products with high amylase activities and at the same time with as little as possible loss of the starch, because starch is a major carbohydrate substrate for beer brewing. On the the other hand, germination is the beginning of a new plant life and accordingly, during the germination, reserve starch is mobilized as much as possible for the growth of the seed- lings. These differences may reflect the contradictions in the results obtained in this and preceding papers.

\section{REFERENCES}

1) G. H. Palmer, J. Inst. Brewing, 78, 326 (1972).

2) C. T. Greenwood and J. Thomson, J. Inst. Brewing, 65, $346(1959)$.

3) C. T. Greenwood and J. Thomson, J. Inst. Brewing, 67, 64 (1961).

4) G. W. Pucher, C. S. Leavenworth and H. B. Vickery, Anal. Chem., 20, 850 (1948).

5) Y. Yano, Am. Soc. Brewing Chemists, Proc., 1971, 27.

6) B. L. Larson, K. A. Gilles and R. Jennes, Anal. Chem., 25, 802 (1953).

7) E. J. Bourne, W. N. Haworth, A. Macey and S. Peat, J. Chem. Soc., 1948, 924.

8) S. Fujimoto, T. Nagahama and M. Kanie, Nippon Nôgeikagaku Kaishi, 46, 577 (1972).

9) S. Oka, S. Shigeta and S. Sato, Agric. Biol. Chem., 35, 1216 (1971).

10) J. E. Hodge and B. T. Hofreiter, "Methods in Carbohydrate Chemistry," Vol. I, ed. by R. L. Whistler and M. L. Wolfrom, Academic Press Inc., New York, 1962, p. 388.

11) T. Yamada and M. Taki, Stärke, 28, 374 (1976).

12) T. Kobayashi, Bull. Agr. Chem. Soc., 19, 163 (1955).

13) S. Hizukuri, S. Tabata and Z. Nikuni, Stärke, 22, 338 (1970).

14) J. M. Bailey and W. J. Whelan, J. Biol. Chem., 236, 969 (1961).

15) G. N. Bathgate and G. H. Palmer, Stärke, 24, 336 (1972).

16) Y. Kano, Sapporo Bîru Kenkyû Naihô (private), 11, 1 (1968).

17) T. Kobayashi and M. Kadowaki, Nippon Nôgeikagaku Kaishi, 27, 599 (1953).

18) T. Fukui, M. Fujii and Z. Nikuni, Nippon Nôgeikagaku Kaishi, 38, 262 (1964).

19) Y. Kano, Bull. Brewing Sci., 23, 1 (1977).

20) Z. Nikuni, Chôri Kagaku, 2, 6 (1969); Denpun Kagaku, 22, 78 (1975).

21) D. French, Denpun Kagaku, 19, 8 (1972).

22) S. Kiribuchi and M. Nakamura, Nippon Nôgeikagaku Kaishi, 47, 333 (1973).

23) S. Kiribuchi and M. Nakamura, Nippon Nôgeikagaku Kaishi, 47, 341 (1973). 